\title{
Tecnologia na Educação: O Pensamento Computacional e a Computação Desplugada como forma de Inclusão Digital
}

\author{
Anelise L. Kologeski ${ }^{1}$, Vithória da S. Batista ${ }^{1}$, Rafaela da S. Bobsin' ${ }^{1}$, Richard W. P. \\ Espíndola $^{1}$, Natália B. Nunes ${ }^{1}$, Maurício B. Julio ${ }^{1}$, Júlia dos S. Martins ${ }^{1}$, Aline S. de \\ Bona $^{1}$
}

${ }^{1}$ Instituto Federal de Educação, Ciência e Tecnologia do Rio Grande do Sul (IFRS) Campus Osório

\author{
Rua Santos Dumont, 2127 - Albatroz, Osório - RS, 95520-000 \\ anelise.kologeski@osorio.ifrs.edu.br, vithoria.sbatistalgmail.com, \\ rafaela.bobsin03@gmail.com, richardpottespindola@gmail.com, \\ nataliabernunes@gmail.com, mauriciobragajulio@gmail.com, \\ jugife.jmegmail.com, aline.bonadosorio.ifrs.edu.br
}

\begin{abstract}
This experience report addresses the practice of playful workshops, involving dynamics with the use of unplugged computing and digital resources, to approach content that involves computational thinking and logical reasoning in the classroom, targeting students in the final series of elementary school. The activities developed were attended by 401 people, from 16 different institutions, between the years 2017 and 2019. The results obtained show improvements in the comprehension of statements of up to $30,4 \%$, pointing out the use of digital information and communication technologies in education can make difference in student learning.
\end{abstract}

Resumo. Este relato de experiência aborda a prática de oficinas lúdicas, envolvendo dinâmicas com o uso de computação desplugada e recursos digitais, para a abordagem de conteúdos que envolvam o pensamento computacional e o raciocínio lógico em sala de aula, tendo como público-alvo os alunos das séries finais do ensino fundamental. As atividades desenvolvidas contaram com a participação de 401 pessoas, oriundas de 16 instituições diferentes, entre os anos de 2017 e 2019. Os resultados obtidos mostram melhorias na compreensão de enunciados de até 30,4\%, apontando que o uso de tecnologias digitais de informação e comunicação na educação pode fazer a diferença na aprendizagem dos estudantes.

\section{Introdução}

A oferta de atividades de extensão está associada a demanda da comunidade, que surge por meio de um desejo mútuo proveniente do interesse e da necessidade da comunidade e da disponibilidade da instituição de ensino parceira. Tendo em vista o uso da prática extensionista, surgiu a ideia de um projeto no qual são apresentados os conceitos básicos de programação em escolas de ensino fundamental, estimulando a participação dos estudantes mediante o uso de atividades lúdicas, envolvendo o raciocínio lógico e o pensamento computacional. A motivação para o desenvolvimento deste projeto é dividida em duas partes essenciais. A primeira delas consiste na divulgação da própria instituição de ensino para a comunidade local, que muitas vezes desconhece sua respectiva qualidade, sua gratuidade, os cursos oferecidos, e o público-alvo da instituição. Já a segunda, consiste na 
necessidade de melhorias na educação básica, que podem ser realizadas com o desenvolvimento do raciocínio lógico e do pensamento computacional, de forma lúdica, tanto com o uso de recursos digitais quanto com o uso da computação desplugada. De acordo com [Brackmann, 2017], o termo "pensamento computacional" consiste em uma distinta capacidade criativa, crítica e estratégica humana de saber utilizar os fundamentos da Computação nas mais diversas áreas do conhecimento, com a finalidade de identificar e resolver problemas de forma colaborativa utilizando passos claros de tal maneira que uma pessoa ou uma máquina possam executá-los com eficiência. Já o termo "computação desplugada" define a ausência do uso de computadores em atividades que envolvem jogos e quebra-cabeças ${ }^{1}$.

A principal justificativa para a necessidade de melhorias na educação básica é apresentada com base nos dados divulgados no ano de 2018 pelo Índice de Desenvolvimento da Educação Básica ${ }^{2}$ (IDEB), para as séries finais do ensino fundamental. O IDEB é obtido por meio da Prova Brasil, realizada pelo Governo Federal e serve para analisar a qualidade do ensino oferecido pelo sistema educacional brasileiro, levando em conta a aprovação escolar e o desempenho dos estudantes em língua portuguesa e matemática. Em nenhuma das três últimas edições da prova foi alcançada a meta nacional esperada. Além disso, se os dados da plataforma do IDEB forem analisados pontualmente para as cidades que fazem parte do Litoral Norte Gaúcho, região onde este projeto é executado, essa diferença se torna ainda mais expressiva. De acordo com a plataforma Agenda $2020^{3}$, existe uma falta de desenvolvimento educacional que está ligada diretamente ao IDEB em nosso estado, e uma das causas é a "Inadequação da educação escolar às exigências do século XXI", apontando que há poucos indícios de práticas inovadoras nas escolas.

Outro fator que impacta diretamente na qualidade da educação é o acesso à tecnologia. Conforme dados disponibilizados em 2018 pela Agência de Notícias do Instituto Brasileiro de Geografia e Estatística ${ }^{4}$, dos 37,2 milhões de estudantes com 10 anos ou mais, apenas $81,2 \%$ utilizaram a Internet no período da pesquisa. Contudo, este resultado cai para 75\% quando são analisados apenas os estudantes de escolas públicas, mostrando assim que $1 / 4$ dos estudantes não faz uso da Internet no seu cotidiano. Considerando-se toda a população brasileira (não apenas estudantes), das 63,4 milhões de pessoas com 10 anos ou mais de idade que não utilizaram a Internet durante o período considerado, $37,8 \%$ não sabiam usar e $37,6 \%$ alegaram falta de interesse, enquanto $14,3 \%$ não acessaram por considerar o serviço caro. Isso mostra que muito ainda deve ser investido para que o acesso à tecnologia seja de fato uma realidade para todas as pessoas, aplicando as tecnologias digitais de informação e comunicação em espaços formais e não formais de educação, usando-as para aprimorar os conhecimentos e auxiliar nas atividades diárias de qualquer indivíduo. Desta forma, fica evidente a necessidade de alguma providência para que o acesso à tecnologia e a qualidade da educação sejam melhorados, proporcionando inclusão digital para todos, permitindo que o acesso aos recursos tecnológicos se torne um hábito no ambiente educacional e no cotidiano de todas as pessoas. Por isso, este trabalho propõe o uso de computação desplugada e de recursos

\footnotetext{
${ }^{1} \mathrm{http}: / /$ csunplugged.org/

2 http://portal.inep.gov.br/ideb

${ }^{3}$ https://agenda2020.com.br/

4 http://shorturl.at/beN34
} 
digitais em oficinas lúdicas, oferecidas para a comunidade, tendo como público-alvo os alunos de nono ano do ensino fundamental, a fim de estimular a inclusão digital, o pensamento computacional e a capacidade de raciocínio lógico dos participantes.

O trabalho está organizado da seguinte maneira: na Seção 2 a revisão de literatura é apresentada, a fim de justificar a necessidade da proposta deste trabalho; na Seção 3 a metodologia desta experiência é descrita; na Seção 4 os resultados obtidos por meio das oficinas promovidas são discutidos; e na Seção 5, as considerações finais são apresentadas, bem como a perspectiva de trabalhos futuros.

\section{Revisão de Literatura}

Diversos trabalhos foram e ainda são desenvolvidos para promover melhorias na educação, com a inserção de programação básica no ensino fundamental. Um exemplo é o trabalho de [Sousa et al., 2018], em que alunos entre sete e oito anos participaram de oficinas, inicialmente sem a utilização de computadores. Após a realização das oficinas, foi possível observar que $100 \%$ dos alunos gostaram de participar das atividades propostas pelos autores. Além disso, as respostas obtidas para a pergunta " $O$ que é lógica de programação?", feita aos participantes, foram coerentes, mostrando que os conceitos transmitidos foram devidamente compreendidos. Ainda, por fim, foi relatado que os participantes passaram a ficar mais animados para as aulas após a experiência com as oficinas.

Também é possível encontrar trabalhos em que novas plataformas, com o intuito de ensinar Programação de forma lúdica, estão sendo desenvolvidas. Um exemplo é a plataforma desenvolvida por [Mattos et al., 2018]. Ela utiliza jogos com cores chamativas, a fim de atrair o público alvo da plataforma. Ela tem por objetivo ensinar programação e desenvolver o pensamento computacional. A plataforma foi testada durante os anos de 2017 e 2018, com turmas de alunos entre sete e treze anos. Foi constatado que os alunos, ao participarem das oficinas, adquiriram mais concentração nas aulas e melhoram suas respectivas habilidades em Matemática.

Além dos trabalhos já citados, existem diversos outros trabalhos que desenvolvem atividades dentro do mesmo contexto, como é o caso de [Gomes et al., 2015] [Schoeffel et al, 2015] [Kologeski et al., 2016] e [Andrade et al., 2016], que compartilham de um único objetivo em comum: despertar o interesse e a criatividade dos estudantes da Educação Básica utilizando atividades dinâmicas que estimulam a aprendizagem e a criatividade.

Com a revisão bibliográfica, foi observado que o ensino de programação e raciocínio lógico com atividades lúdicas não é uma novidade no meio acadêmico, já que muitos projetos possuem propostas similares ao trabalho aqui descrito, utilizando metodologias e ferramentas semelhantes. Contudo, cada projeto tenta contribuir para a melhoria da educação em suas respectivas comunidades, abrangendo as mais diversas regiões do Brasil. A partir disso, surgiu a ideia de realizar um projeto onde escolas pertencentes à região de abrangência da instituição promotora, que compreende o Litoral Norte do Estado do Rio Grande do Sul, seriam convidadas para a participação de oficinas diferenciadas do ensino tradicional em sala de aula (normalmente conteudista e expositivo), promovendo o estímulo ao raciocínio lógico e ao pensamento computacional por meio do uso de atividades lúdicas, oferecendo assim uma oportunidade de inclusão digital para muitos dos jovens participantes. 
VIII Congresso Brasileiro de Informática na Educação (CBIE 2019)

Anais dos Workshops do VIII Congresso Brasileiro de Informática na Educação (WCBIE 2019)

\section{Metodologia}

As oficinas oferecidas visam desenvolver importantes habilidades de raciocínio lógico e pensamento computacional, a fim de impactar diretamente no aprendizado, na tomada de decisões, na compreensão de enunciados e na capacidade de raciocínio dos estudantes, contribuindo, a longo prazo, para o propósito de melhorar o cenário educacional do país. Com estratégias atrativas e diversificadas, como as apresentadas nesta seção, é possível promover uma educação integral, cidadã e de qualidade. Com as oficinas realizadas os participantes podem aprender noções da área tecnológica por meio de atividades que envolvem a programação básica, despertar o interesse e a curiosidade pela Computação e também obter um aprendizado significativo e efetivo para ser aplicado nas decisões do seu cotidiano, seja na escola ou em outros diferentes ambientes da vida pessoal do estudante.

As oficinas permitem relacionar diferentes conteúdos com as atividades, envolvendo principalmente noções matemáticas, interpretações de textos, raciocínio lógico e pensamento computacional, favorecendo uma educação integral, como defende a Base Nacional Comum Curricular ${ }^{5}$ (BNCC). Conforme a BNCC, os processos de resolução de problemas, de investigação, de desenvolvimento e modelagem de projetos podem ser citados como formas privilegiadas da atividade matemática, que são potencialmente ricos para o desenvolvimento do letramento matemático (raciocínio, representação, comunicação e argumentação) e pensamento computacional.

Diante deste contexto, as atividades proporcionadas visam estimular o desenvolvimento da lógica e da criatividade dos participantes com o uso da computação desplugada e de recursos digitais, trabalhando com a correta compreensão de um enunciado, fazendo uso de temas e personagens atuais conhecidos pelos jovens participantes. Para o desenvolvimento do raciocínio lógico e do pensamento computacional, optou-se por utilizar diferentes recursos disponíveis de forma gratuita nas plataformas Scratch $^{6}$, Code $^{7}$ e Pensamento Computacional ${ }^{8}$.

A plataforma Scratch foi alvo de estudo das oficinas realizadas no ano de 2017, e cada participante teve a oportunidade de criar o seu próprio jogo. Um exemplo de atividade desenvolvida foi o jogo da corrida, conforme apresenta a Figura 1, onde os participantes criaram o cenário, escolheram os personagens, e realizaram a programação necessária para que os personagens pudessem competir. Um passo a passo da execução desta atividade pode ser encontrado dentro da própria plataforma, no formato de tutorial.

A plataforma Code tem sido adotada nas três edições do projeto (2017, 2018 e 2019) por ser intuitiva, divertida e atrativa aos olhos dos participantes, oferecendo diversos tipos de jogos, que abordam temas como noções espaciais de direita/esquerda, comandos condicionais, laços de repetição e conscientização ecológica através de atividades que envolvem a coleta de lixo e reciclagem. As tarefas desenvolvidas durante a aplicação das oficinas utilizaram os seguintes jogos digitais: "A Fazendeira", "Labirinto Clássico", "Star Wars" e "Minecraft". Um exemplo de atividade pode ser observado na Figura 2, com o cenário e os comandos utilizados para um dos jogos trabalhados. Como algumas

\footnotetext{
${ }^{5} \mathrm{http} / / /$ basenacionalcomum.mec.gov.br/

${ }^{6}$ https://scratch.mit.edu/

${ }^{7}$ https://code.org/

${ }^{8}$ http://www.computacional.com.br/
} 
VIII Congresso Brasileiro de Informática na Educação (CBIE 2019)

Anais dos Workshops do VIII Congresso Brasileiro de Informática na Educação (WCBIE 2019)

escolas não possuem laboratório de informática, a maioria das oficinas que fizeram uso da plataforma Code foram realizadas em nossa própria instituição de ensino.

Para as oficinas do ano de 2019, decidimos inserir, em conjunto, atividades de computação desplugada, para facilitar o atendimento às escolas que não possuem computadores ou acesso à internet. As atividades desenvolvidas foram a "Programação em Papel Quadriculado", com objetivo de executar comandos para formar uma figura dentro de uma grade de papel quadriculado, conforme apresenta-se na Figura 3, e o jogo de tabuleiro "Estacionamento Algoritmico", da plataforma Pensamento Computacional, onde um veículo específico deve ser removido para fora do tabuleiro, após uma sequência de determinados comandos de movimentação, conforme apresenta-se na Figura 4. Ambas as atividades oferecidas serviram para a introdução dos conceitos de programação, com o uso de comandos simples representados por setas, que fazem parte do contexto das atividades que compreendem a computação desplugada.

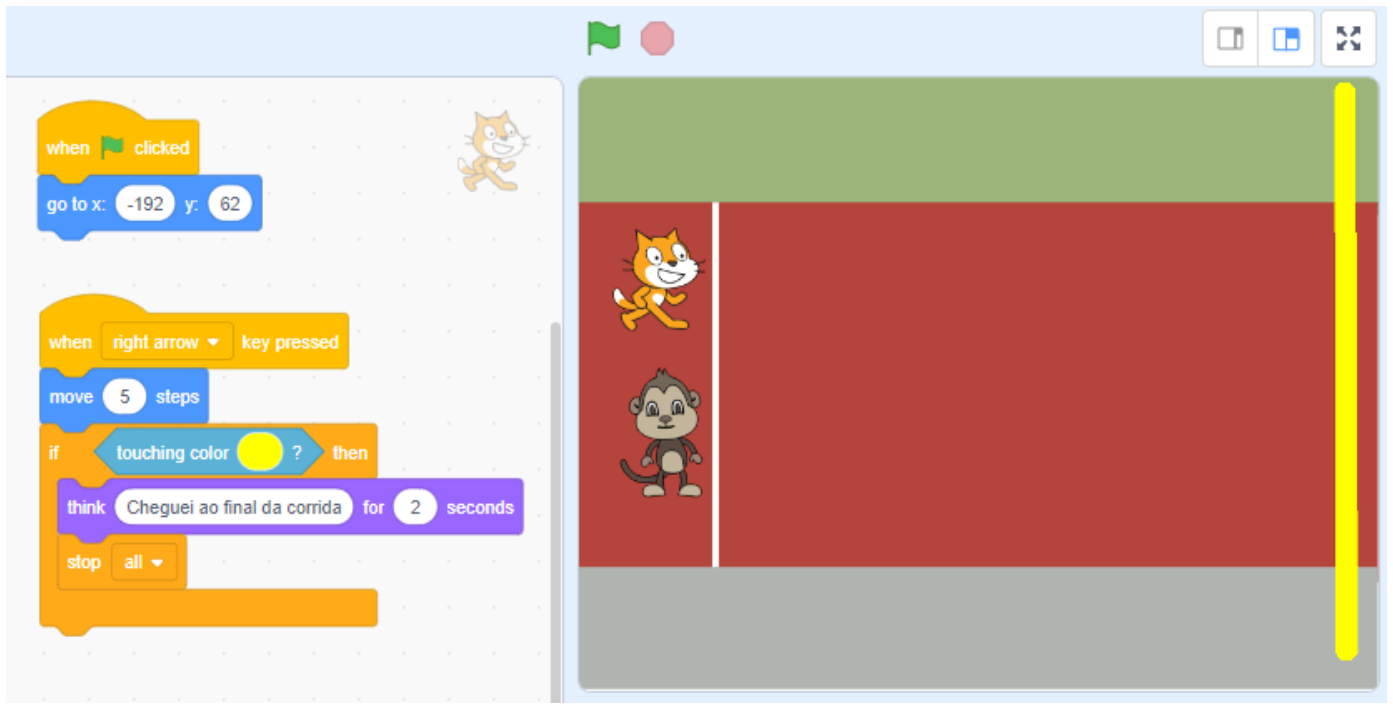

Figura 1. Jogo da corrida desenvolvido com a plataforma Scratch.

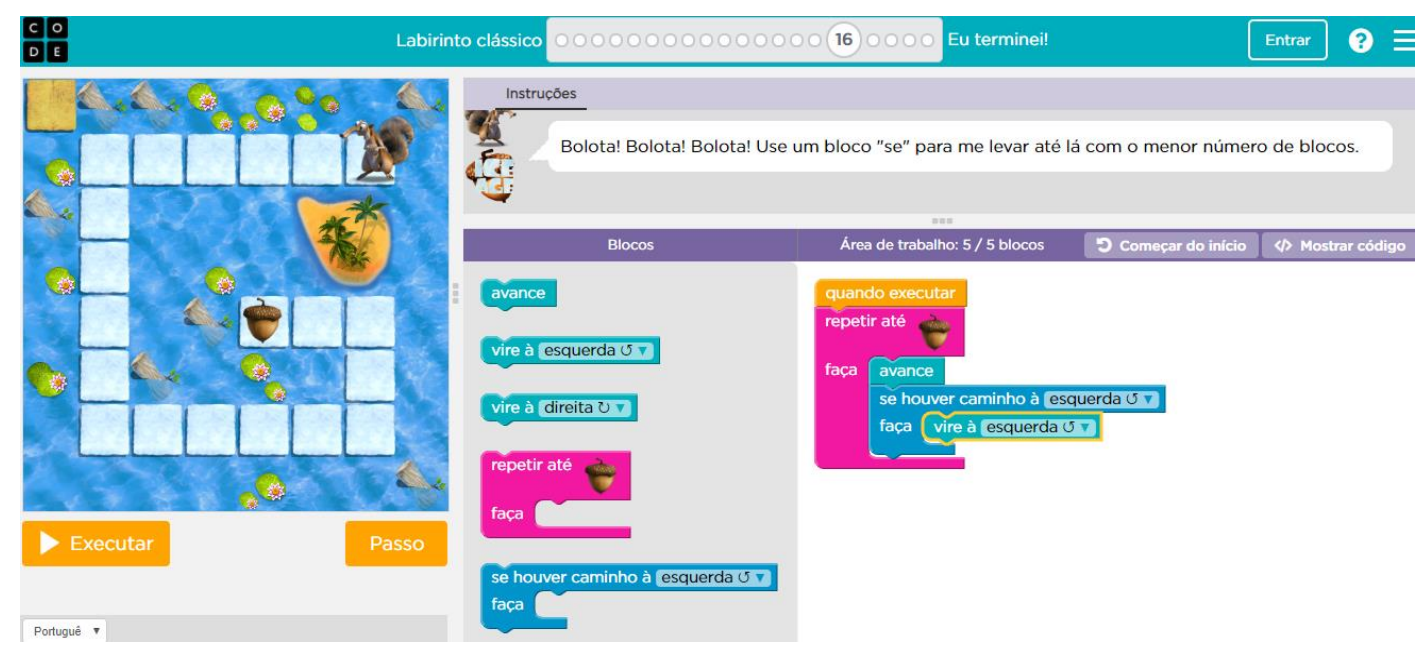

Figura 2. Cena do jogo "Labirinto Clássico" oferecido pela plataforma Code. 

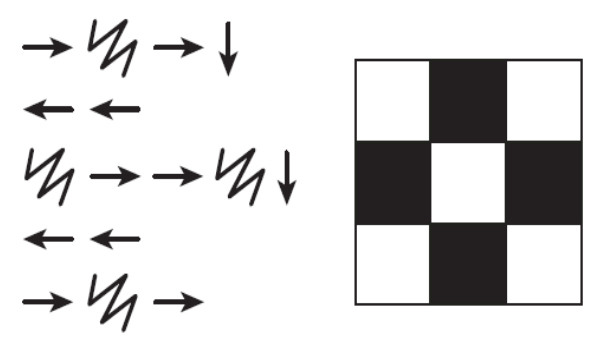

Figura 3. Exemplo de atividade com a Programação no Papel Quadriculado da plataforma Code.
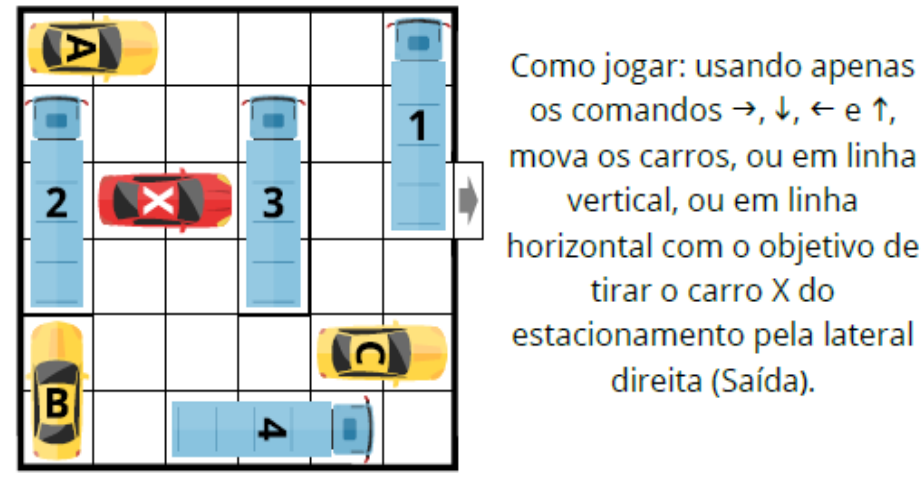

\begin{tabular}{|c|c|c|c|c|c|}
\hline VEÍCULO & \multicolumn{5}{|c|}{ MOVIMENTOS } \\
\hline$C$ & $\leftarrow$ & $\leftarrow$ & $\leftarrow$ & & \\
\hline 1 & $\downarrow$ & $\downarrow$ & $\downarrow$ & & \\
\hline$A$ & $\rightarrow$ & & & & \\
\hline 2 & $\uparrow$ & & & & \\
\hline$B$ & $\uparrow$ & & & & \\
\hline 4 & $\leftarrow$ & $\leftarrow$ & & & \\
\hline 3 & $\downarrow$ & $\downarrow$ & & & \\
\hline$X$ & $4 x$ & $\rightarrow$ & & & \\
\hline
\end{tabular}

Figura 4. Exemplo da atividade com o Estacionamento Algorítmico da plataforma Pensamento Computacional.

Cada oficina inicia com a realização de um teste, nomeado de "Pré-Teste", que tem por objetivo analisar o nível de conhecimento prévio dos alunos, antes da realização da oficina. Após o término da oficina, outro teste é realizado, nomeado de "Pós-Teste", possibilitando analisar o desempenho obtido pelo aluno durante as atividades desenvolvidas. Estes testes são constituídos por 5 questões objetivas, que são comparadas ao final da oficina, para que a evolução do aluno seja observada. O conteúdo de cada questão envolve a interpretação do enunciado com os comandos trabalhados durante a execução das oficinas, oferecendo ao estudante 3 alternativas de resposta para cada questão, sendo apenas uma delas correta.

Durante as oficinas cada participante avança as etapas do jogo no seu próprio ritmo, utilizando os conhecimentos adquiridos durante a execução da oficina, pedindo auxílio aos bolsistas do projeto quando enfrentam dificuldades. Todas as atividades envolvem a capacidade de interpretação de texto do estudante, bem como o raciocínio lógico, para que o aluno consiga atingir os objetivos propostos por cada atividade, normalmente executados no formato através de uma sequência de passos bem definidos, como em um algoritmo.

Como normalmente os alunos participam da oficina em seus respectivos horários de aula, as atividades trabalhadas variam de acordo com o conteúdo que os professores responsáveis pelas turmas querem propor aos alunos. Em geral, as oficinas acontecem no horário disponibilizado pela escola, e a duração das oficinas varia entre 1 hora e 30 minutos e 4 horas. 
VIII Congresso Brasileiro de Informática na Educação (CBIE 2019)

Anais dos Workshops do VIII Congresso Brasileiro de Informática na Educação (WCBIE 2019)

\section{Resultados}

Até o presente momento, o projeto já contabilizou a participação de 16 instituições de ensino distintas, oferecendo um total de 26 oficinas, contando com a participação de 401 estudantes. Ao longo das edições do projeto, algumas instituições se repetem, bem como os alunos participantes que estiveram presentes nas duas modalidades de oficinas de 2019 . Desta forma, foram atendidos 59 participantes no ano de 2017, 142 participantes no ano de 2018, e 200 em 2019, sendo 169 deles nas oficinas com computação desplugada e 141 nas oficinas com a plataforma Code, conforme apresenta Tabela 1. A métrica utilizada para mensurar o aprendizado dos alunos foi a comparação entre o Pré-Teste e o Pós-Teste, compostos por 5 questões objetivas, como já mencionado anteriormente. Desta forma, com base nas respostas fornecidas para os testes, verifica-se a existência de melhorias nos resultados finais, evidenciando um aprendizado de fato por parte dos participantes, após a realização das oficinas. Em todas as edições do projeto é possível observar que houveram melhorias nestes resultados, conforme apresenta a Figura 5.

\begin{tabular}{|c|c|c|}
\hline Ano & Total de Instituições e Oficinas & Participantes \\
\hline 2017 & 1 Instituição e 4 oficinas (Scratch e Code) & 59 \\
\hline 2018 & 8 Instituições e 7 oficinas (Code) & 142 \\
\hline \multirow{2}{*}{2019} & 8 Instituições e 8 oficinas (Computação Desplugada) & 169 \\
\cline { 2 - 3 } & 11 Instituições e 7 oficinas (Code) & 141 \\
\hline
\end{tabular}

Tabela 1 - Adesão das instituições e dos participantes. Fonte: Autoria própria.

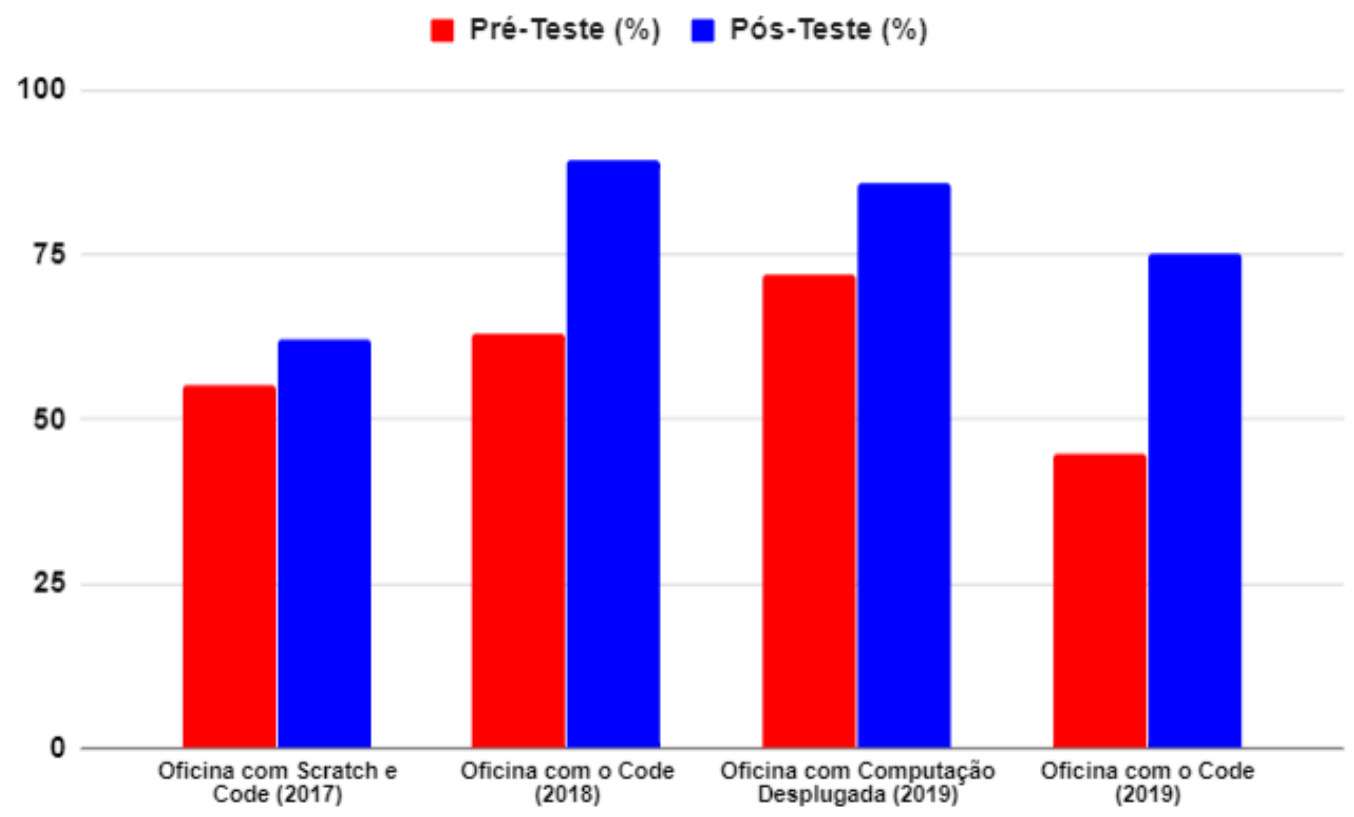

Figura 5. Síntese (\%) dos resultados obtidos com o Pré e o Pós-teste, em cada tipo de oficina. Fonte: Autoria própria.

Desta forma, com base nos resultados apresentados, torna-se notável a evolução na aprendizagem dos participantes por meio das oficinas oferecidas. A oficina com o menor rendimento (apenas 7\% de melhoria) foi a oficina que incluiu o uso do Scratch, que durou apenas 1 hora e 30 minutos. Diante deste resultado optou-se por não utilizar esta plataforma 
nos anos seguintes, uma vez que mais tempo seria necessário para explorá-la adequadamente. Já para os outros tipos de oficinas, a melhoria foi de 26,4\% em 2018, 14\% para a oficina com computação desplugada em 2019, e 30,4\% para a oficina com o Code, também de 2019. Diante dos resultados apresentados, observou-se que a oficina com a computação desplugada teve um menor rendimento (com melhoria de apenas 14\%) porque inicialmente os alunos obtiveram um resultado alto no Pré-Teste, chegando a $72 \%$ de acertos. Isso significa que o conhecimento prévio dos alunos, no que diz respeito à computação desplugada, já é demasiadamente satisfatório, e por isso o resultado do PósTeste não apresentou uma melhoria expressiva (apenas 14\%). Uma discussão entre a equipe de execução nos fez refletir sobre este resultado, nos levando a acreditar que este tipo de atividade foi executada de forma fácil pelos estudantes, uma vez que a prática de computação desplugada não constitui uma novidade para muitos destes estudantes que já estão familiarizados com jogos de tabuleiros e sequências de instruções.

Além dos resultados quantitativos apresentados, juntamente com as questões do Pós-Teste, foi disponibilizado aos participantes das oficinas de 2019 um campo descritivo para que, de maneira espontânea, eles registrassem sua respectiva percepção das atividades desenvolvidas, bem como suas experiências, críticas ou sugestões. A grande maioria dos relatos recebidos até o momento são de elogios ou sugestões construtivas, que contribuíram de forma positiva para motivar a equipe de execução a continuar aplicando o projeto nas escolas da região do Litoral Norte do Rio Grande do Sul. Abaixo segue uma breve síntese dos 132 relatos recebidos de forma espontânea, dos estudantes que participaram das oficinas com a plataforma Code no ano de 2019:

- 94,7\% (125 pessoas) dos relatos são algum tipo de elogio, como: "Gostei", "Legal", "Boa oficina", "Interessante", dentre outros;

- 24,2\% (32 pessoas) dos relatos também expressaram a satisfação por terem aprendido algo novo ou então reconhecem a importância do tema trabalhado;

- 5,3\% (7 pessoas) relataram ter dificuldades com os conteúdos trabalhados, achando as atividades complicadas;

- $1,5 \%$ ( 2 pessoas) acharam a oficina muito simples;

- $0,7 \%$ (1 pessoa) não gostou da oficina.

Por se tratar de um resultado obtido mediante uma análise qualitativa das oficinas, abordando os participantes de forma voluntária, foi então possível entender o grau de satisfação dos mesmos. Com base nestes resultados, concluiu-se que uma análise qualitativa de dados pode ser tão importante quanto uma análise quantitativa, ainda mais num cenário tão complexo como é o caso da educação, servindo então de motivação para a equipe de execução continuar aplicando o projeto.

Além dos resultados obtidos por meio dos testes, no ano de 2018 a equipe de execução do projeto também decidiu observar a quantidade de alunos que participaram das oficinas e que resolveram ingressar na instituição, por meio do processo seletivo 2019/1, escolhendo um dos cursos de Ensino Médio oferecidos, sendo eles o Curso Técnico em Informática Integrado ao Ensino Médio e o Curso Técnico em Administração Integrado ao Ensino Médio. Dos 142 participantes das oficinas do ano de 2018, 34 deles se inscreveram para a realização do processo seletivo 2019/1, que aconteceu em dezembro de 2018, sendo 17 inscritos para o Curso Técnico em Informática e 17 para o Curso Técnico em 
VIII Congresso Brasileiro de Informática na Educação (CBIE 2019)

Anais dos Workshops do VIII Congresso Brasileiro de Informática na Educação (WCBIE 2019)

Administração. Este resultado superou as expectativas da equipe de execução do projeto, surpreendendo de forma muito positiva a todos, concluindo que o propósito de divulgação da nossa instituição de ensino, também foi devidamente atendido.

\section{Considerações Finais}

Diante das dificuldades apresentadas pelos índices do IDEB, que mostram uma compreensão insuficiente dos estudantes na interpretação de texto ou em aspectos relacionados à compreensão da matemática, que podem afetar diretamente todas as outras áreas de conhecimento, surgiu a ideia do desenvolvimento e da execução de um projeto de extensão, com o uso de atividades simples e lúdicas que abordam o estímulo do raciocínio lógico, proporcionando um aprendizado mais significativo para os participantes, a fim de contribuir para uma educação integral, diversificada e de qualidade.

Assim, este artigo teve como intuito relatar a experiência de um projeto de extensão que leva programação básica para alunos das séries finais do ensino fundamental, de forma dinâmica, a fim de contribuir para o desenvolvimento do raciocínio lógico e pensamento computacional de todos os envolvidos, na região do Litoral Norte do Rio Grande do Sul.

As atividades realizadas nas oficinas visam não só estimular o raciocínio dos participantes, mas também apresentar um pouco da ideia inicial da programação, que é algo cada vez recorrente no cotidiano das pessoas que vivem em sociedade. Além disso, muitas pessoas acreditam que este seja um tema de difícil compreensão, quando, na verdade, a programação não passa de uma sequência de instruções lógicas e bem definidas para atingir um objetivo também bem definido. Então, mediante atividades simples e divertidas que abordam este assunto, tentamos desmistificá-lo desde cedo, sabendo que os jovens atendidos pelo projeto usarão destes conhecimentos para atividades cotidianas e, especialmente, para atingirem o mercado de trabalho atual que tanto necessita de conhecimentos voltados à tecnologia.

Para isso, são utilizadas atividades em que os participantes precisam seguir ou construir algoritmos para atingir um determinado objetivo. Desenvolvendo atividades desta maneira, oriundas de plataformas gratuitas, espera-se que os participantes passem a olhar de outra maneira para os problemas comuns que envolvem certas situações do cotidiano, interpretando-as com maior eficiência e buscando por formas de resolvê-las com mais praticidade, observando principalmente que normalmente existem múltiplas soluções possíveis para que um mesmo objetivo seja atingindo.

Para mensurar os resultados obtidos com o projeto, um teste no início e no final das oficinas é aplicado. Ao todo foram realizadas 26 oficinas ao longo dos três anos de projeto, atendendo um total de 401 pessoas, apresentando melhorias na compreensão de enunciados pelos participantes de até $30,4 \%$. Desta forma, fica claro que com o decorrer das oficinas, os conceitos e atividades trabalhadas puderam facilitar a compreensão de enunciados pelos participantes, e que atividades lúdicas diferentes do ensino tradicional de sala de aula podem proporcionar melhorias no raciocínio lógico, motivando os estudantes na aprendizagem de conteúdos essenciais para a resolução de problemas diários.

Ao longo da execução das oficinas, percebeu-se a dificuldade da participação de muitas escolas diante da ausência de computadores. Por isso, em 2019 as oficinas passaram por uma adaptação, permitindo a divisão em duas categorias, usando recursos digitais e computação desplugada. Algumas das escolas participantes, diante da disponibilidade, 
VIII Congresso Brasileiro de Informática na Educação (CBIE 2019)

Anais dos Workshops do VIII Congresso Brasileiro de Informática na Educação (WCBIE 2019)

acabaram então optando pela participação das duas modalidades, enquanto outras participaram apenas da modalidade com computação desplugada.

Até o presente momento, as oficinas com computação desplugada contaram com apenas duas atividades (Programação no Papel Quadriculado e Estacionamento Algorítmico), sendo que para o futuro a equipe de execução pretende incorporar novas atividades, para que diferentes modos de aprendizagem sejam explorados. Espera-se também conseguir atender mais alunos, oferecendo uma oportunidade de ensino diferenciada para um maior número de escolas, contribuindo para a formação integral e cidadã dos estudantes participantes das oficinas, tornando assim o aprendizado deles um momento de compartilhamento de saberes, atrativo e gratificante para todos os envolvidos, além de proporcionar a inclusão digital para aqueles que não possuem contato diário com os mais diferentes recursos tecnológicos.

\section{Referências}

Andrade R.; Mendonça J.; Oliveira W.; Araujo A. L.; Souza F. Uma Proposta de Oficina de Desenvolvimento de Jogos Digitais para Ensino de Programação. Congresso Brasileiro de Informática na Educação (CBIE), 2016.

Brackmann, Christian. Desenvolvimento do Pensamento Computacional Através de Atividades Desplugadas na Educação Básica. Universidade Federal do Rio Grande do Sul (UFRGS), Porto Alegre, RS, Brasil, 2017.

Gomes T.; Barreto P.; Lima I. R. A.; Falcão T. P.. Avaliação de um Jogo Educativo para o Desenvolvimento do Pensamento Computacional na Educação Infantil. Congresso Brasileiro de Informática na Educação (CBIE), 2015.

Kologeski, A.; Barbosa, D. N. F. ; Miorelli, S. T. ; Grings, C. (2016). Logicando: Ensinando Lógica com as Tecnologias da Informação. In: XV Seminário Internacional de Educação, 2016, Novo Hamburgo. XV Seminário Internacional de Educação Educação e Interdisciplinaridade: Percursos Teóricos e Metodológicos, 2016.

Mattos M. M.; Kohler L. P. A.; Zucco F. D.; da Cunha K. Z.; Hein N.; Santos B. F. F.; da Silveira H. U. C.; Giovanella G. C.; Fronza L.; Schlögl L. E. Ensino do pensamento computacional em escola pública por meio de uma plataforma lúdica. Congresso Brasileiro de Informática na Educação (CBIE), 2018.

Schoeffel P.; Moser P.; Varela G.; Durigon L.; de Albuquerque G. C.; Niquelatti M. Uma Experiência no Ensino de Pensamento Computacional para Alunos do Ensino Fundamental. Congresso Brasileiro de Informática na Educação (CBIE), 2015.

Sousa T. G.; Nunes M. M.; Martinhago A. Z.; Nunes M. M. Uso da lógica de programação para potencializar o pensamento criativo em crianças do ensino básico. Congresso Brasileiro de Informática na Educação (CBIE), 2018. 